Unity Journal

Vol. III, 205-219, 2022

Doi: https://doi.org/10.3126/unityj.v3i01.43326

Prithvi Narayan Shah Research Center

Directorate General of Military Training, Nepali Army

Kathmandu, Nepal

\title{
Role of Nepali Army in Promotion and Preservation of Nepalese Art, Culture, and Traditions
}

Uddhav Gautam

\begin{abstract}
The Nepali Army was founded initially as the Gorkha Army around 450 Years ago. Since its inception, the Nepali Army as the nation's largest organization has not only been ensuring our territorial integrity but has also been connecting multi-ethnic, multi-lingual, multi-religious, multi-cultural Nepalese society in a common thread by preserving its rich tangible and intangible cultural heritages along with the associated traditions. In this regard, this study predominantly illuminates the fact that modern-day Nepal has been shaped through the sacrifices of the Nepali Army and their histories are interwoven altogether. This research illustrates that the Nepali Army has been preserving and promoting Nepalese art, culture, and tradition for centuries both in times of peace and war. Despite socio-economic and political shifts in the nation's history over time, the Nepali Army has remained resolute in its spirit assimilating various cultural transplants within the organization promoting cultural relativism. Within this frame of reference, this study primarily aims to unfold major hurdles the Nepali Army is currently facing in the conundrum of operational and ceremonial duties along with the impacts of modern world issues, such as digitization
\end{abstract}

and modernization. To fulfil these objectives, this study follows a qualitative research methodology. It analyzes data collected from various primary and secondary sources and analyze it to draw out relevant inferences. I explore the military institution's roles to promote arts and cultures based on quantitative data with qualitative analysis.

Keyword: Nepali Army, Nepalese culture, the role of the Army, multi-ethnic, Heritage

\section{Introduction}

Every soldier in the Nepali Army has a dual identity: cultural and national. The cultural identity comes from his/her community while national identity is him/her being a citizen of a sovereign nation, Nepal. This concept of dual identity is completely different from dual identity as a citizen-soldier concept in the U.S. Army (Vest, 2012). In contrast, dual identity in Nepali Army is a result of multiculturalism. Even though Nepal occupies a small strip of land in between the Indian sub-continent and the roof of the world these coordinates have amazingly made Nepal composite a contrasting topography extending from IndoGangetic plains in the south to the top of the world in the north. 
In addition to its topology, predominant factors, such as insulation of the Himalayas when Muslims invaded north India in the thirteenth century and intermediary position in the trade routes between India, Tibet, and China (running along the Kuti pass to the northeast and Kyrong pass to the northwest of Kathmandu Valley) also imbibed cultural pluralism in Nepal. While geographical setting gave rise to distinct cultural heritage primarily due to waves of migration, the isolation aided in preserving prevalent practices from invaders. However, Nepalese culture and tradition evolved as distinct from India and Tibet despite a lot being drawn in cultural exchange as Nepal synthesized an amalgam of Hinduism and Buddhism and harmonized them which is evident from numerous existing rituals. For instance, both Buddhists and Hindus worship deities like Vajrayogini, Mahakala, Ajima. This religious spectrum also contains Animism and Shamanism (Sharma, 1983). Thus, various regions of Nepal kept on developing under different ethnic communities being ruled by different dynasties such as Kirats, Lichhavis, Thakuris, Mallas and Shahs.

The political unification of modern-day Nepal initiated by King of Gorkha Prithivi Narayan Shah in 1743 A.D. and the development of the modern-day Nepali Army from the Gorkha Army happened simultaneously. Nonetheless, the army with which Prithivi Narayan Shah started his conquest was not as pluralistic. In course of his conquest, Shah created a standing army mixing up soldiers recruited from different fighting castes such as Khas, Magar, Gurung and Thakuri led through command structure with competence holding precedence. Shah believed mixed-up forces could fight strongly (Dibyaupadesh). This belief was fortified by the system of
Jagir (Job/Pay), Bitalap (Revenue free land), and Marawat (land to be given to the persons who sacrifice for the Nation) (Dibyaupadesh). The foundation of the multi-ethnic army was laid down in such a firm manner that by the time the Anglo-Nepal war (18141816) started Nepali Army was composed of diverse ethnic groups which fought as a resilient and extremely resolute national army awing the British (Subba, 2020). Accordingly, multiculturalism and multiethnicism became a part of the Nepali Army and merged mainly since there was no room for individual gladiators and it successfully avoided sectarian distinctiveness cutting the gordian knot by promoting a meritocratic system.

The standpoint approach on Nepalese cultural heritage includes both tangible (artistic creations, built heritage, monuments) and Intangible heritage (performing arts, traditional skills, social practices). While intangible heritage received limelight in the modern world only after 2003 when UNESCO adopted the Convention for the Safeguarding of Intangible Cultural Heritage in Paris (Bortolotto, 2007), the convergence of tangible and intangible heritage has been the central ethos of cultural heirloom in Nepal for generations. For example, a temple in its structure is a tangible heritage that truly exceeds its value only because of the rituals performed by the worshipers, which is the intangible part. The military culture of the Nepali Army is established on the same premise, creating an intergenerational compact between previous and current soldiers drawing inspiration from ancestral heroism and unwavering adherence to practiced customs and traditions.

Nepalese cultural heritage has been growing since time immemorial. Onceinterpreted as the 
land depicting an ideal picture of the Middle Ages of the east by Percy Brown (Brown, 1912) is still home to 125 ethnic groups and 126 languages (Subedi, 2016). Therefore, it does not come as a surprise that every soldier recruited into Nepali Army belongs to one of these communities thus holding a distinct cultural identity and possibly speaking a language only a few do. Nepalese Army is the nation's largest organization, hence is also an abode portraying, promoting, and preserving objective and subjective elements of Nepalese cultural heritage webbed in both implicit and explicit norms (Deaton \& Golubeva, 2020) which it rightfully does through ceremonial duties and practices persisting within the army. On the other hand, Nepali Army also addresses operational duties, of which it carries a great history and culture itself.

\section{Statement of the problem}

It is widely articulated that the history of modern Nepal largely coincides with Nepali Army. The modern-day Nepali Army is obviously in many ways different from the structural vision of the standing army given by Prithivi Narayan Shah in his Dibyaupadesh. Having said that, the kernel that binds it together even as of today is the same as he envisioned i.e., multicultural but equal. Against this backdrop, this research discerns how the Nepalese Army is promoting and preserving Nepalese art, culture, and traditions, its existing and emerging challenges, and the various factors that require attention.

\section{Objectives of the study}

The primary objectives of the study include:

i. To provide an account of the role played by the Nepali Army in the preservation and promotion of Nepalese Art, Culture, and traditions through cultural relativism.

ii. To point out key hurdles in carrying out ceremonial and operational duties as both are equally significant and to suggest essential measures.

iii. To highlight the influence of technological development concerning the role of the army in this context.

\section{Chapter Organization}

Concerning the structure of the paper, I begin with an introduction to multiculturalism in Nepal and the Nepali Army in Chapter 1. Chapter 2 reviews relevant literature then, the research methodology followed by the paper is laid down in detail in chapter 3 . In chapter 4, I discuss the role of the Nepali Army in the promotion and preservation of Nepalese art, culture, and traditions under various sub-headings. Finally, relevant findings and conclusions are summarized in chapter 5 .

\section{Literature Review}

According to Tereza Trencheva and Evelina Zdravkova-Velichkova (2019), conservation of cultural heritage refers to 'a systematic process of search, study, identification, documentation, digitization, registration, digital preservation, conservation, restoration and socialization.' Cultural heritage preservation along with environmental conservation jointly aids in the socioeconomic development of a nation (Wells \& Stiefel, 2018) which in turn conserves an irreplaceable part of the history (Othman \& Heba, 2018) and develops the country as well. Nonetheless, the process of preservation also tends to jeopardize antiquity which creates room for conflict due to a clash of perspectives. On the one hand, it is likely to happen even more in a 
multi-cultural perspective where it is hard to sustain balance while coordinating among various dimensions of a project (Yang et al., 2018). On the other hand, Nepal Army has surprisingly been able to achieve institutional trust in this regard since it is a homogenous public institution that accommodates heterogeneous cultural orientations (Jamil \& Baniamin, 2021) therefore, making it one of the pillars of heritage preservation in Nepal.

Mamta Siwakoti and Sanjay Adhikari, in "Culture in Nepal: An exploration of the legacy and its way forward," found that awareness on the gravity preservation of cultural heritage holds, has tremendously grown in modern time especially post 2015 Earthquake where the majority of historical monuments were partially or completely ruined. For instance, Dharahara, Rani Pokhari, Taleju Temple, Natyeshwor Temple, Kasthamandap, Gaddi Baithak of Hanumandhoka Palace, and 750 more. The researchers list out several ongoing projects (also with international cooperation) striving for renovation and restoration of these cultural sites such as the JFIT-UNESCO Project, Kathmandu Valley Preservation Trust, and Miyamoto Global Disaster Relief, Nepal (Siwakoti \& Adhikari, 2018). The Nepali Army has always been part of this campaign. Disaster Management is a forte and one of the primary operational duties of the army. Besides assisting in rescue and relief missions, it has renovated and restored forts such as Sangurigadhi, Dugunagadhi, Jitgadhi, and others (Nepal Army, 2021). Additionally, it has also been part of uplifting national cultures in various ways, such as performing the endangered Saraya dance in national and international stages highlights that.
In Sipahi 2077, CoAS General Purna Chandra Thapa (Retd.) states about the existence of shared understanding in the Nepalese armed forces among the junior and mid-level leaders comprised of millennials and generation $\mathrm{Z}$, who readily understand the challenges in the Nepalese socio-political and security landscape. He further clarifies that there is a need to find a happy medium between the Army's role in national security which is ever-evolving and its role in confirming people's participation to maintain the organizational culture. While arguing the need for positive change in the organization in light of contemporary issues such as digitization, General Thapa stresses that popular trust is a 'hard-earned heritage' and the need to preserve and promote it amidst incorporating changes in the organizational framework (Thapa, 2020).

The creation of a cyber-resilient army has been one of the core objectives of the Nepal Army in recent times. By developing cyber resilience within the organization, the Nepali Army aims to manage human resources by replacing office runners, file keepers, registration clerks with automation (Nepal Army, 2020). The efforts to link OPS digitization with National Park and Wildlife Reserve Directorate and Disaster Management Directorate have been successful and, further efforts to incorporate technology in other areas have been sped up (Nepal Army, 2021). Although technological enhancement holds great significance in the case of strengthening the armed forces for the digital battlefield, it can equally be of assistance in the promotion of national heritage.

In contrast, it is also essential to note that cultural pluralism in Nepalese society has a side of discrimination, inequality, and superstitions. Nepal is yet to retain a stable 
democratic political culture devoid of corruption even though it has gone through waves of political changes over time (Baral, 2012). Nepal Army faces a challenge to address this cultural pluralism as an apolitical institution composed heterogeneously.

\section{Research Methodology}

The research follows a qualitative research methodology to attain the previously mentioned objectives. The epistemology will primarily be pragmatic integrating available perspectives to interpret the available information. I analyze data collected from various primary and secondary sources and draw out relevant inferences. The nature of the data will be primary as well as secondary. The primary data collected for this purpose have been done through interviews of NA's WWII veteran Subedar Nar Bahadur Basnet (Retd.) and Capt. Subash Thapa from The Directorate of Public Relations and Information of Nepal Army as well as response received to a structured questionnaire. On the other hand, secondary sources include the study of journal articles, books, reports, thesis, and additional credible information. The military institution's role in promoting arts and cultures is grounded on quantitative data with qualitative analysis.

\section{Role of Nepali Army in Promotion and Preservation of Nepalese Art, Culture, and Traditions}

Firstly, it is essential to know the reason behind the Army actively participating in heritage preservation. Army Act, 2063 Section 4 defines the reason for establishment of the Nepal army as:

"The Nepal Army shall be established for the protection and Defence of the independence, sovereignty, territorial integrity and national unity of the state of Nepal."

and also by the Section 3 of Nepal Army Religious Practices Directive, 2076 which states that religious and cultural practices will be preserved and promoted.

Even though the duty to preserve the national heritage can be interpreted from these sections, the historical reason behind this duty of Nepal Army is older than the Army Act, 2063 and the directive. When asked about the reasons why cultural practices matter in Nepali Army, WWII veteran Subedar Nar Bahadur Basnet (Retd.) of Ganesh dal battalion (now) said, "I have been around since the time of Chandra Sumsher. Before Hindustan gained independence in year 5, I was on the Pakistani front in the world war... Fauj (Army) is a way of life, every day before PT and meal in the morning we used to go pray at Ganeshthan..." (Nar Bahadur Basnet, Personal Communications, 26 October 2020). Two points in his statement provide a vivid picture of cultural embeddedness in the Nepali Army. One, Nepal Army is not a job but a way of life, and second, it is not by chance NA significantly contributes to cultural preservation. It is preserving its own identity through practice.

In the modern era, Nepal Army has elevated its operational competencies to a multidimensional level. Besides involving itself in a combat role, it is also responsible for disaster management, developmental activities, peacekeeping operations, and more. On a different note, Nepal Army also pays homage to its diverse heritage by being a part of and celebrating various festivals and practicing a wide range of traditions. On the whole, NA performs routine ceremonies and occasional ceremonies. Routine ceremonies 
are the ones celebrated every year like Bhoto Jatra, Indra Jatra, Phulpati, and national days. Meanwhile, Occasional ceremonies include the ceremonies scheduled as per requirement. It includes funeral ceremonies, Wreath laying, and Guard of honor.

The Nepalese calendar is manifested with various days of traditional significance apart from the major festivals such as no moon day or Ekadashi. Nepal Army practices all these traditions as well. For example, The Army mess doesn't serve meat on the day of Ekadashi and Aunshi (no moon day). In the monsoon, the army celebrates ropain on Ashar 15 by having Dahi(curd) and chiura (beaten rice). On 15th Shrawan, it also celebrates kheer khane din. Sankrantis are also auspiciously celebrated. Many cultural practices that are rarely performed in modern times are practiced within the Nepal Army. These traditions as mentioned in the Nepal Army Religious Practices Directive, 2076 under schedule 1 no. 3 as other cultural practices and traditions are listed as below:

1. Nawa Barsa (New Year) on Baishak 1: Formal wishes.

2. Akshaya Tritiya on Baishak and Shukla Tritiya: Saatusarbat preparation in the Mess.

3. Buddha Jayanti on Baishak Shukla Purnima: Buddha puja in barracks around Stupas.

4. Ropain Parwa on Ashar 15: Dahi (Curd) and Chiura (Beaten Rice) in the Army Mess.

5. Shrawan Sankranti on Shrawan 01: Special dishes as per tradition in the mess.

6. Kheer Khane din on Shrawan 15: kheer in the Army mess.

7. Naag Panchami on Shrawan Shukla Panchami: Naag Puja.
8. Janai Purnima on Shrawan shukla Purnima: Janai and Rakshyabandhan puja.

9. Kushe Aunshi on Bhadra Krishna Aunshi: Kush puja in the puja room.

10. Teej ko Dar on Bhadra Shukla Tritiya: Dar for female soldiers.

11. Shree Krishna Janmastami on Bhadra Krishna Astami: Shree Krishna Puja.

12. Shree Bishwakarma Puja on Ashwin 1: weapons and vehicles puja.

13. Kaag Tihar on Kartik Krishna Trayodashi: Kaag puja and feeding.

14.Kukur tihar on Kartik Krishna Chaturdashi: Kukur puja and feeding.

15.Laxmi Puja on Kartik Krishna Aunshi: Laxmi Puja

16. Govardan Puja on Kartik Shukla Pratipada: Cow/Ox/Govardan puja

17. Swasthani Bratarambha Purnima on Poush Shukla Purnima: Swasthani Brata Puja

18. Maghe Sankranti on Magh 1: Dishes according to tradition.

19. Shree Panchami on Magh Shukla Panchami: Saraswati Puja

20. Swasthani Brata Samapti Purnima on Magh Shukla Purnima: Ending puja

21. Shivaraati on Falgun Krishna Trayodashi: Special puja and other traditions.

22. Faagu Purnima on Falgun Shukla Purnima: celebrated as per traditional practice.

23. Ghode Jatra on Chaitra Krishna Aunshi: Demonstration in Sanik Manch

24. Ram Nawami on Chaitra Shukla Nawami: Shree Ram Puja 
Further the days on which vegetarian food is prepared has also been enlisted as:

1. Ekadashi throughout the year (24)

2. Aunshi throughout the year (12)

3. Akshaya Tritiya (1)

4. Budhha Jayanti (1)

5. Guru Purnima (1)

6. Naag Panchami (1)

7. Shree Krishna Janmaastami (1)

8. Shree Swasthani Brataarambha (1)

9. Shree Panchami (1)

10. Shree Swasthani Brata samapti (1)

11. Mahashivaratri (1)

12. Shree Ram Nawami (1)

There are specific battalions within the Nepal Army namely Purano Gorakh and Kali Bahadur that recruit particular castes only as suggested by Prithivi Narayan Shah in Dibyaupadesh. Purano Gorakh enlists only Magars while Kali Bahadur enlists Gurungs. As a cultural practice in Purano Gorakh, Bangur (a cross between a domestic pig and wild boar) is prepared in the army mess. Both Purano Gorakh and Kali Bahadur are quite liberal in the use of alcohol for enlisted ranks like no other battalions in the Nepal Army, an exception also mentioned by Prithivi Narayan Shah in Dibyaupadesh. Another battalion named Ripumardan contains only the Rai caste. While other Nepali castes practicing Dashain put Rato (red) tika, Rai community are known to put Seto (white) tika. Even the officers of different castes put Seto (White) tika in the Ripumardan battalion. Similarly, Naya Sabuj is another battalion created after 2006 that recruits the Chaudhary and Tharu communities only. (Capt. Subash Thapa, Personal Communication, 24 November
2021).

In the public domain, the army celebrates the main festivals of Nepal like Dashain, Tihar, Jatras. On Phulpati, the 7th day of the Dashain, NA is responsible for bringing the Kalash filled with holy water, jamara, banana stalks, and sugarcane covered with a red cloth with the Brahmans from the Gorkha Durbar on a decorated palanquin under a gold-tipped and embroidered umbrella. This tradition is centuries old. The units in the valley do 'phulpati badhai' with a parade while the entire valley resonates in gunfire (Elias \& Burbank, 2014). The CoAS performs Kot Puja at the dashain ghar in Hanuman Dhoka in Mahanawami (9th day of Dashain). Similarly, Army Day is celebrated on the day of Mahashivaratri. This practice has been prevalent since 1935. On this day, NA exhibits a wide range of drills. It showcases its competencies and demonstrates its arsenal in the Army Day. Within the Kathmandu valley, the newar community celebrates numerous Jatras every year like Bhoto Jatra, Indra Jatra, Ghode Jatra. NA is a major part of these processions. For instance, when the chariot of Rato Machhendranath is pulled in Rato Machhendranath Jatra, NA is responsible for the security of the chariot.

Moreover, NA is also responsible for several ceremonies of national importance such as Republic Day, Democracy Day, Martyrs Day. The following figure represents the number of troops from each battalion deployed in the number of ceremonies throughout 2018. The recent data isn't used for this article because ceremonies have been symbolic due to the COVID-19 impact. 


\section{Figure 1}

Number of troops from each battalion of valley division in ceremonial activities.

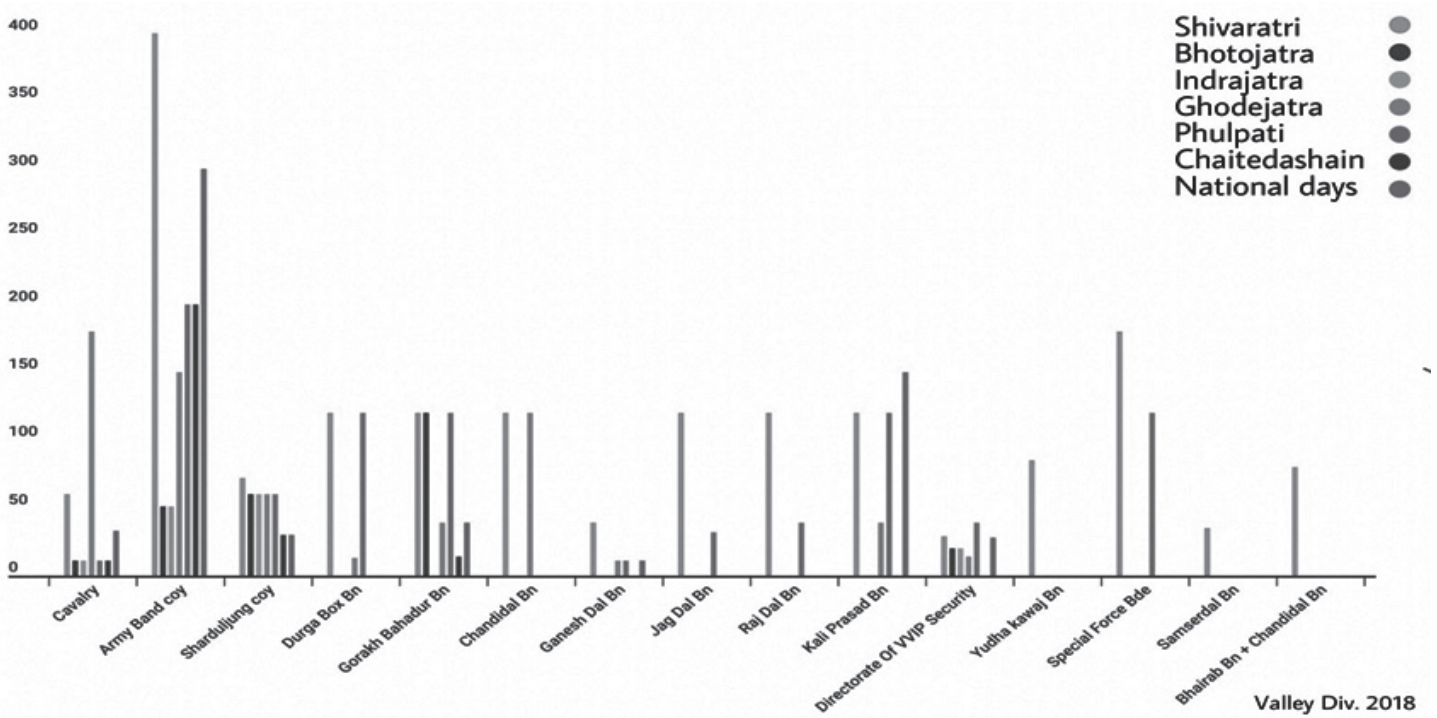

Note. This chart was drawn by the researcher from the data available from the valley division. Copyright 2018 by the valley division of the Nepal Army

Figure 2

Percentage of soldiers from different ethnic backgrounds

Note. This pie figure was drawn by the researcher from the data available from the military archive of $C B S$ 2011. Copyright Nepal Army, Bhadrakali.

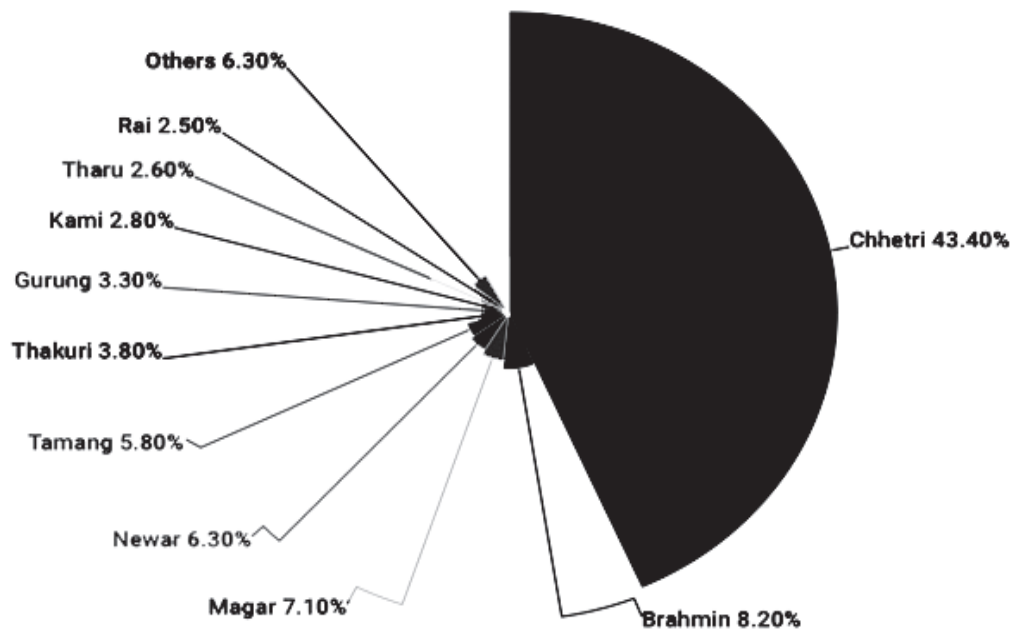

The chart above

demonstrates the number of soldiers in the Nepal Army coming from various ethnic communities. These figures also depict the religious and cultural tolerance within the institution. A soldier of any caste might be involved in the practice and performance of any festival. Thus, harmonization of traditions and the value of operational duty both exist in Nepal Army. When I asked Subedar Nar Bahadur Basnet about the value of duty for a soldier he 
replied "In year 3, when we returned from the world war, king Tribhuwan called upon us and said 'What do you want?' I replied, I did my duty sarkar, I want nothing..." (Nar Bahadur Basnet, Personal Communications, 26 October 2020).

It is argued that a serious attempt to preserve and promote Nepalese artistic heritage is yet to be made from the side of the government. In recent years particularly after the $60 \mathrm{~s}$ art theft has risen substantially throughout Nepal (Sharma, 2001). An effort to preserve art heritage has been made through National Museum and the Military Museum. The national museum was first established as Chauni Silkhana (Arsenal) in 1926 (Sharma, 1983). National Museum which is guarded by Nepal Army is the largest in the country. It holds a variety of treasures, including wooden and stone sculptures, ornamental arts, paintings, historical weaponry, coins, and stamps, among others. The museum complex is divided into two more structures namely Juddha Jatiya Kalashala and the Buddhist Art Gallery. Stone sculptures, metal works, old paintings, and woodworks are among the pieces on show in Juddha Jatiya Kalashala. The galleries are divided into five sections: stone, terracotta, painting, wood, and bronze. Similarly, In the Buddhist Art Museum the Terai, Kathmandu, and Northern Himalayan Sections are on the ground floor, while the Mandala Section is on the first floor, with statues, paintings, and ceremonial art objects presented in three dimensions (Rana, 2015). The Military Museum displays military art heritage through various sections. The victories and battle of Nepalese army in form of oil paintings have been displayed in war memorial section of the museum. Likewise, paintings of various kings and army chiefs have been displayed in supreme commander section. The forts section of the museum has preserved the representation of various forts. War memorial section of the museum has the pictures and memoirs of Nepalese army expeditions and wars. The machineries used in manufacture of Gehendra Rifle has been shown in the weaponry section of the museum. Marcus Ray (2016) mentions that Nepal was self-sufficient in production of adequate military rifle when it used to produce Gehendra Rifles. National Art Gallery of Bhaktapur Durbar Square established in 1960/61 that houses paintings also an important place guarded by Nepal Army.

Musical instruments are also a significant part of the cultural heritage. Due to the diversity, there are a lot of musical instruments in Nepal. In the history of the Nepali Army alone, from the time of Prithivi Narayan Shah, the usage of 27 types of musical instruments for various reasons can be traced. These instruments include Gorakhali dhol, Mauri Baja, Muchurga, Ghorau, Paluwa, Nagbeli, Karnali Baja, Bag Mukhe Bano, Sahit Dine Nagara, Indra Dhol, Dundubhi, Tasha, Bheri, Baano, Turanga, Sikhar, Bishannad, Turahi, Paashupat Damaru, Shringinaad, Trisul Damaru, Nagara Nishan, Naagfani, Kaura Khaijadi, Raani Maadal and Maajhwaal Bansuri (Kandel, 2020). These instruments were played strategically and tactically. Some instruments like Sahit dine Nagara, Gorakhali dhol, Ghorau were used for motivation before battle, while some like Naagbeli, Nagara Nishan were used for intelligence purposes (Kandel, 2020). These instruments hold great significance for the Nepali Army and Nepalese cultural heritage.

For centuries Nepal Army has been preserving musical tradition. The Sharduljung gulma always plays Indradhol in Indrajatra. Likewise, Gurujyu paltan 
plays Tasa in numerous military ceremonies. Bheri is another instrument played by the Nepali Army in Bhairavi Temple, Nuwakot. Furthermore, Paashupat damaru and Trishul damaru have emotional and psychological significance for Nepal Army. One of the most seen instruments that the Nepal Army plays is the Majhwaal Bansuri, an instrument played by Gurujyu Paltan (Kandel, 2020).

\section{Figure 3}

Purano Gorakh Dal performing Maruni Nach

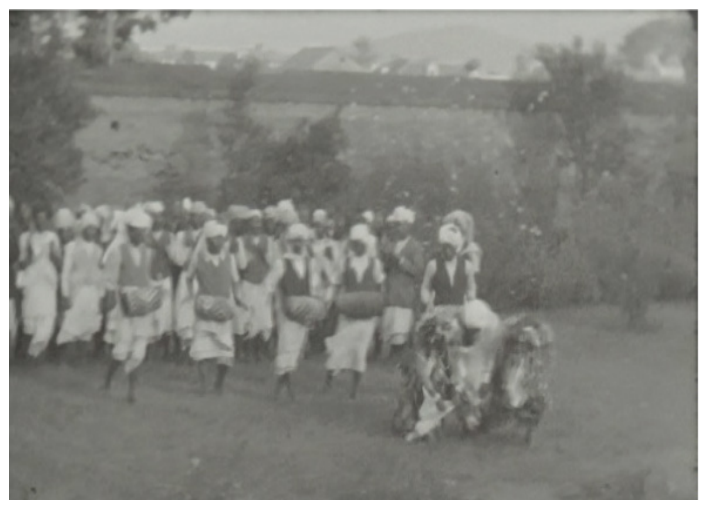

Note. This picture was taken in 1988 by a Dutch musician Arnold A. Bak. Copyright Sipahi 2020

\section{Figure 4}

\section{Gurujyu Paltan in Indra Jatra}

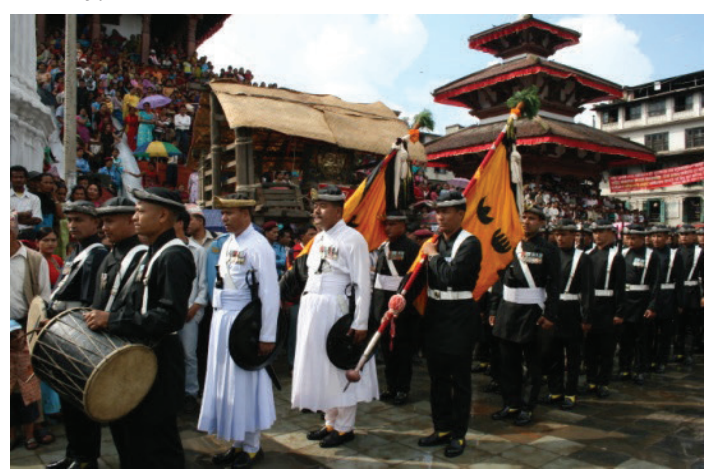

Language is also an essential element of cultural heritage. Nepali is the most spoken language in Nepali Army. 'Salaam' is used in Nepali Army for salutation. It is a verbal and symbolic representation of commitment towards the duty. It has been taken from Urdu. There are several words like 'asawab khana', 'kawaaj', 'sais', 'adab', 'topkhana' which hold linguistic value in the Nepali language. This vocabulary is preserved by the Nepali army (Shrestha, 2020).

The army is the 'cementing force' that joins societies (Shrestha \& Khadka, 2015). There is a lot of symbolism in the Nepal Army with which it binds its troops together. When Prithivi Narayan Shah created the first five companies, he named them after a particular deity. The practice has been followed while raising any unit within the Nepali Army. Every battalion binds its troops together through symbols. Each battalion has a distinct symbol, normally representing the deity after whom the battalion is named. This is done by depicting the picture of the deity or the weapons held. Shree Nath Battalion, raised in 1762 A.D. For instance, has the symbol of Trisul in the middle, sun on the left and sun-moon on the right side and below the trisul depiction of feet of the deity. Likewise, Shree Kalibaksh Battalion has a pictorial representation of Goddess Kali with in 'Astabhuja' form (with eight arms) holding multiple weapons (Aryal, 2020). These symbols are taken and established wherever the unit moves. However, there are symbols of deities such as Shree Mul Nishan, Shree Shree Nath Ganko Nishan which cannot be moved. There is a sense of brotherhood and national unity in these symbols. 


\section{Figure 5}

Symbol of Kali baksh Battalion

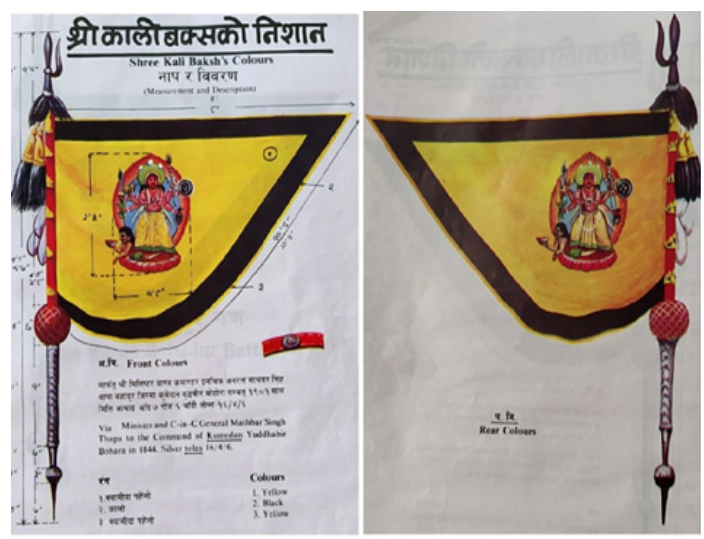

Copyright Nepal Army Press

\section{Figure 6}

Symbol of Shree Nath Battalion

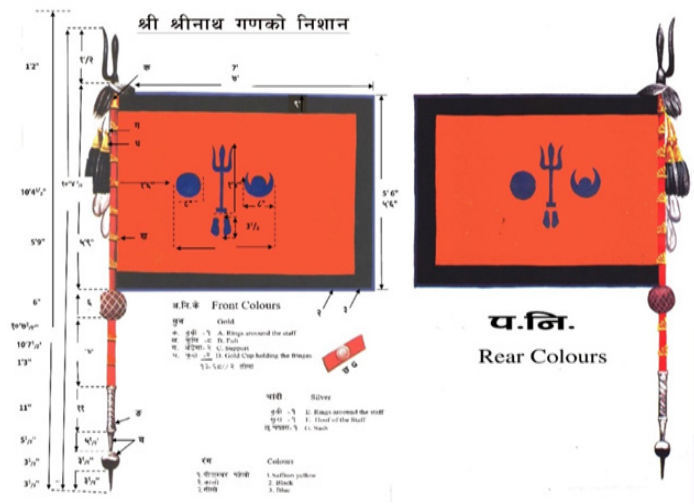

Copyright Nepal Army Press

In Nepalese culture colors are used in various ways. Each shade carries a particular meaning. During every religious activity a certain color is used for a particular activity. The symbolic context of color is crucial in Nepali Army as well. The Nepali Army associates different meaning with primary seven colors which is similar with the cultural practices prevalent in Nepal. The following table demonstrates the meanings behind the colors.
Table 1

Colors and their symbolic meaning

\begin{tabular}{|c|c|c|}
\hline S.N. & Color & Symbol and Meaning \\
\hline 1. & White & $\begin{array}{l}\text { Sattwa/Righteousness } \\
\text { and truth }\end{array}$ \\
\hline 2. & Red & $\begin{array}{l}\text { Rajasee/Passion and } \\
\text { victory }\end{array}$ \\
\hline 3. & Black & $\begin{array}{l}\text { Tamasic/Destruction } \\
\text { and Resistance }\end{array}$ \\
\hline 4. & Blue & Tranquility and peace \\
\hline 5. & Yellow & $\begin{array}{l}\text { Awareness } \\
\text { knowledge }\end{array}$ \\
\hline 6. & Green & Nature \\
\hline 7. & Sky Blue & $\begin{array}{l}\text { Incomprehensible and } \\
\text { earnest }\end{array}$ \\
\hline
\end{tabular}

The use of colors is done while worshiping gods and their symbols. As per Army Miscellaneous Service Regulation, 2074 Section 3, competent priests are recruited to carry out the religious and traditional practices in the Nepal Army. These priests according to the religious ceremony follow associated traditions while worshiping a particular deity and celebrating a certain festival (Aryal, 2020). For instance, in monthly Satyanarayan puja Crimson, Yellow, Red and White colored cloth are used while in every Paakshik puja red and white colored cloth with other materials are used.

\section{Digitization in the Nepali Army and preservation of cultural heritage}

Conversion of information of an analogue carrier like text, audio, and video signals into digital version through, for instance, scanning method to process, store and transmit the available information in a digital form via the internet, computers, satellite, social 
networks, knowledge databases regardless of geographical constraint is known as digitization (Traykov et al,. 2016). The primary objective of digitization of cultural heritage is to aid in preserving cultural artifacts digitally through digital libraries and providing global access (Marinov, 2019). Despite its objective significance, the process of digitization is not an easy task (Borisova, 2008). Digital documentation poses two problems: (1) the information needs to retain its original value, (2) documentation might not be comprehensive, it might not include specialized terminology, fragments, and other cultural phenomena. The world has now transcended to an 'information society' (Petrov et al., 2017). The Nepal Army has also incorporated this definition of the new age within the institution in varied forms. One of which includes heritage conservation.

The adaptation of digitization in preserving cultures and traditions is vivid in Nepal Army. The digitized publications like Newsletters, Sipahi, Sipahi Fortnightly, Sipahi Special Issues, Unity Journals are perfect examples. The premise I have built this paper on, which includes articles and information derived from the online articles and publications of the Nepali Army, is also an instance of a digitization milestone. The YouTube channel and radio channels of the Nepal Army also regularly produce new content. It displays the commitment of the Nepal Army not only to enhance Civil-Military relations but also to promote and archive the heritage. In reply to what can the Nepali Army do for heritage conservation? Subedar Nar Bahadur Basnet said," Prabidhi (Technology) has increased so much today... It is an age where you have to know by studying, the things we learned by experiencing" (Nar Bahadur Basnet, Personal Communications, 26th August 2020).
The Nepali Army has established Integrated Data Center that facilitates Maps, VTC, Data Storage, and Backup. It has also moved forward in digital archiving, data access, and security measures. Development of a Digital Archiving Application done through outsourcing is also in the final stage. The implementation of the software system has started through the tasks.nepalarmy.mil.np domain. After initiating digital archiving, Nepal Army has already archived more than 47,947 crucial historical artifacts of Nepalese cultural heritage. Moreover, the security of storage and backup of such archived materials through a specialized data center is under process. A plan to establish Integrated Data Center Monitoring \& Security Protocol is under process (Nepal army, 2021).

Digitization of cultural heritage requires the strategic implementation of several scholars and specialists. The issues in ownership of the digital materials and archives also need to be taken into account (Borissova, 2008) but, issues of Intellectual Property Law don't fall under the domain of objective relevance of this paper.

\section{An analysis of existing challenges in the Nepal Army's role:}

Nepal Army is addressing every role with exceptional efficiency. The military is mobilized in times of peace as well as war. In times of peace, Army works in fields relating to the development, disaster management, and others as mentioned in Article 267 of the Constitution of Nepal. Military forces remain prepared for unforeseen circumstances. Therefore, recruitment, training, and professional growth are given utmost priority in the organization. In this way, the operational calendar of the Nepal Army has various duties. In the current scenario, 
there is a clash between the operational and ceremonial duties in the Nepal Army. There are many hurdles in carrying out the role of 'preserver' and 'promoter' of cultural heritage in the conundrum of operational and ceremonial duties. The existing challenges can be generalized in light of the following points:

1. Lack of manpower: Each unit is assigned both operational and ceremonial tasks. As the strength is divided, there are compromises due to insufficient manpower.

2. Resources crunch: Every task assigned to the army requires specialized equipment and materials also economic resources. Nepal army is known for generating efficient results from little resources, however the available resources still reduce the efficiency many times.

3. Lack of time: Troops are not only responsible for the ceremonial calls but also their operational readiness. They are required to maintain their professional competence. Thus, they need to complete training and various courses. The clash of these duties makes it harder for them to manage time.

4. Sole effort: NA is always being ambassador for promoting and preserving Nepalese culture and tradition. The determined effort of NA has been somehow successful to safeguard cultural and traditional ethos of Nepal. However, NA's effort is limited within four walls of the barracks and some religious and cultural places only. The incorporation of various organization including Government of Nepal (GoN) and other stakeholders helps to influence general public to promote and support NA's relentless effort to preserve Nepalese culture and tradition. The only combined effort can bring profound effect that NA has been envisioned for. Thus, NA should also act as messenger and focal point in this regard to further its goal.

5. Cultural and traditional dilemma: The cultural and traditional dilemma is still in infant phase and has slim chance to contest the existing effort of NA. However, it is necessary to uproot this dilemma before it gets germinated. The sentiments attached with various religion and culture can ignite clash inferno, so NA should be well guarded to combat such situation.

6. Modernization effort and internal problem: NA has been going through the dire situation in these days. The quest for modernization and the problem of retention and recruitment are at tipping point in NA. These kinds of problems have been enforcing NA to distract from ceremonial duties. On the other hand, Covid-19 is being invincible problem to perform ceremonial duties. Thus, the resolute hunt to fulfill its historical duties can serve as launch pad to expand the spectrum of preservation and promotion of the cultural heritage of Nepal.

\section{Conclusion}

I tried to illustrate the silent role played by the Nepali Army in the preservation and promotion of Nepalese cultural heritage by using qualitative methodology in this article. Nepal Army is the nation's oldest and largest organization has carried a significant history in shaping modern-day Nepal. Modern-day Nepal and the Nepali Army share a common history of origin and glorification. The cultural practices of Nepal are shared as well. The Army is committed to the protection of territorial integrity and sovereignty, but it is equally devoted to preserving and promoting the cultural heritage of the nation. Various practices prevailing in the army are a part of the multicultural identity that Nepal holds. This is highlighted by objective and 
subjective elements of both tangible and intangible heritage which the Army has been practicing for centuries. Numerous paradigms are emerging in the modern world. Digitization is also one of them. Due to the development of cyberspace as a tactical ground, Nepal Army has started to advance in the field. It has also taken steps to digitize national heritage to promote its identity on a global scale. Even though this study primarily emphasizes the praiseworthy role of the Nepal Army in conserving and fostering national heritage, it also suggests that there is also a need to strike a balance between ceremonial and operational efficiency. There are some impediments in carrying out both of these duties simultaneously. If it successfully manages to overcome them, it can address them effortlessly.

The Nepal Army is known throughout the world for its ferocious warfare capabilities. Yet, little is said about the roots of its strength, the culture to the outside world. Due to the incorporation and practice of the cultural elements belonging to each caste, race, and ethnicity in Nepal, the Nepal Army has proved unity in diversity. NA is always being ambassador for promoting and preserving Nepalese culture and tradition. The determined effort of NA has been somehow successful to safeguard cultural and traditional ethos of Nepal. However, NA's effort is limited within four walls of the barracks and some religious and cultural places only. The incorporation of various organization including Government of Nepal (GoN) and other stakeholders could be instrumental to influence general public in its trails of preservation and promotion of the cultural heritage of Nepal. The only combined effort can bring profound effect that NA has been envisioned for. NA should also act as messenger and focal point in this regard to further its goal. Thus, the resolute hunt to fulfill its historical duties can serve as launch pad to expand the spectrum of preservation and promotion of the cultural heritage of Nepal.

\section{References}

Aryal, N. P. (2020). Nepali Senama Nishaanko parampara ra aitihasik adhyaan. Sipahi, 165172.y

B. Marinov, Digital image processing. Accessed on: 16.03.2019. Retrieved from http://www. uacg.bg/filebank/acadstaff/userfiles/study bg_425_DIP_L01-04.pdf

Baral, B. (2012). Culture and Internal Security of Nepal (Master's dissertation). Faculty of the U.S. Army Command and General Staff College, Kansas. https://apps.dtic.mil/sti/pdfs/ ADA562879.pdf

Borissova, V. L. (2008). Cultural Heritage and Intellectual Property.

Bortolotto, C. (2007). From Objects To Processes: Unesco's "Intangible Cultural Heritage. Journal of Museum Ethnography, 19, 21-3 http://www.jstor.org/stable/40793837

Brown, P. (1912). Picturesque Nepal. London: A. and C. Black.

Celestial Advice (Dibaya-upadesh) Prithivi Narayan Shah. (n.d.). Nepal Law Commission. https://www.lawcommission.gov.np/en/wpcontent/uploads/2018/09/dibbaya-upadeshof-prithivi narayan-shah.pdf

Constitution of Nepal. (2015). Nepal Law Commission. https://www.lawcommission. gov.np/en/category-prevailing-lawconstitution

Elias, J., \& Burbank, J. (2014). Nepal. Cavendish Square Publishing, LLC.

Jamil, I., \& Baniamin, H. M. (2021). How culture may nurture institutional trust: Insights from Bangladesh and Nepal. Development Policy Review, 39(3), 419-434.

Kandel, R. P. (2020). Yasari Prayog Garinthyo 27 Baajaa. Sipahi, 13-19. 
Lantz-Deaton, C., \& Golubeva, I. (2020). Intercultural competence for college and university students: a global guide for employability and social change. Springer Nature.

Nepal Army. (2020). Digital Nepali Senako Awadharana tatha Bhabisyako Cyber Resilient Nepali Sena. Sipahi Bisesanka, 75-77.

Nepal Army. (2021). Digitization tarfa sudrit pahalkadami. Sipahi Pakshik, 9-10.

Nepal Army. (2021). Raastriya Ekatako Adhaar: Akikaran Marga Karyakram. Sipahi Pakshik, 12-13.

Nepal Law Commission. (2063). Army Act, 2063.

Othman, A. A. E., \& Heba, E. (2018). Adaptive reuse: an innovative approach for generating sustainable values for historic buildings in developing countries. Organization, technology \& management in construction: an international journal, 10(1), 1704-1718.

Petrov, P. S., Dimitrov, G. P., Parusheva, S. S., Nikolov, N. S., \& Petrova, S. D. (2017). Improving the Performance of Social Assisted Search in Library Information Systems. In 4th International Multidisciplinary Scientific Conference On Social Sciences And Arts Sgem 2017 (pp. 311-318).

Rana, K. (2015). Nepalese History Museum. Research Gate. https://www. researchgate.net/profile/Kritika-Rana/ publication/343671387_A_Thesis_Report on_Designing_Nepalese_History_Museum/ links/5f37b70992851cd302f7c5b8/A-ThesisReport-on-Designing-Nepalese-HistoryMuseum.pdf

Ray, M. (2016). Nepalese Arms Manufacture and General Gehendra. Journal of the Historical Breechloading, 8.

Sharma, J. L. (1983). A brief note on museum development in nepal. Ancient Nepal: Journal of Department of Archaeology, 76, 1-3. http://www.digitalhimalaya.com/collections/ journals/ancientnepal/index.php? selection $=76$

Sharma, P. R. (2001). Gods Are Leaving the Country: Art Theft From Nepal. Contributions to Nepalese Studies, 28(1), 131-138.
Sharma, P. R. (1983). Nepali Culture and Society: A Historical Perspective. Contributions to Nepalese Studies, 10(1), 1-20.

Shrestha I. K. \& Khadka, D. B. (2015). Naagarik ko Najarma Nepali Sena. Sipahi, 123-124.

Shrestha, D. R. (2020). Nepali Senako Pratik Chinha. Sipahi, 19-24

Siwakoti, M., \& Adhikari, S. (2018). Culture in nepal: An exploration of the legacy and its way forward. Kathmandu School of Law Review, 6(2), 105-127.

Subba, P. (2020). Sources of Nepali Army's military effectiveness during the Anglo-Nepal War. Unity Journal, 1, 114-119.

Subedi, M. (2016). Caste/ethnic dimensions of change and inequality: implications for inclusive and affirmative agendas in Nepal. Nepali Journal of Contemporary Studies, 16(1), 1-16.

Thapa, P. C. (2020). Developing A Shared Understanding in Nepali Army: Lesson for Future Leaders. Sipahi, i-v.

Traykov, M., Trencheva, M., Mavrevski, R., Stoilov, A., \& Trenchev, I. (2016). Using partial differential equations for pricing of goods and services. Scientific Annals of Economics and Business, 63(2).

Trencheva, T., \& Zdravkova, E. (2019). Intellectual Property Management In Digitization And Digital Preservation Of Cultural Heritage. EDULEARN19 Proceedings. .

Vest, B. M. (2013). Citizen, Soldier, or Citizen-Soldier? Negotiating Identity in the US National Guard. Armed Forces \& Society, 39(4), 602-627. https://doi. org/10.1177/0095327X12457725

Wells, J. C., \& Stiefel, B. L. (eds.). (2018). Human-centered built environment heritage preservation: Theory and evidence-based practice. Routledge.

Yang, Y., Shafi, M., Song, X., \& Yang, R. (2018). Preservation of cultural heritage embodied in traditional crafts in the developing countries. A case study of Pakistani handicraft industry. Sustainability, 10(5), 1336. 